\title{
KERANGKA KERJA PERENCANAAN PENGEMBANGAN PRODUK SEBAGAI PENINGKATAN DAYA SAING INDUSTRI KECIL MENENGAH
}

\author{
Broto Widya Hartanto ${ }^{1^{*}}$ dan Subagyo ${ }^{1}$ \\ ${ }^{1}$ Departemen Teknik Mesin dan Industri \\ Fakultas Teknik Universitas Gadjah Mada \\ Submisi: 17-05-2018; Revisi: 28-08-2018; Diterima: 31-08-2018
}

\begin{abstract}
This study developed a new product development planning framework for small and medium enterprise (SME) in creative industry sector to increase the business competitiveness. The development process referred to the stages of design science research. The development stage adapted the first two stages of the modular function deployment (MFD), those are the description stage of consumer need through the house of quality, and functional decomposition. The study explained that the application of MFD adaptation is effective and adequate to the creative SME condition. The technical concepts were able to be screened and scored by using pugh selection matrix. However, every technical concepts could not be described into detailed domain functions and means. Therefore, the addition of methods applied in parallel was carried out, that is the concept decomposition with the function means tree, and the technical solution synthesis with the axiomatic design so that the design process is easier to handle. It's recommended to eliminate the zigzagging process in axiomatic design, since it has been done on the function means tree and the use of customer relationship management data base to support voice of customer.
\end{abstract}

Keywords: Competitiveness; Functional decomposition; New product development; Quality function deployment; Small medium enterprise.

\begin{abstract}
ABSTRAK
Penelitian ini bertujuan membangun kerangka kerja perencanaan pengembangan produk baru bagi industri kecil menengah (IKM) sektor kreatif untuk meningkatkan daya saing usaha. Proses pembangunan mengacu pada tahapan design science research. Tahapan pengembangan mengadaptasi dua tahapan awal modular function deployment (MFD), yaitu tahapan deskripsi kebutuhan konsumen menggunakan house of quality, dan dekomposisi fungsional. Penelitian menjelaskan bahwa penerapan adaptasi MFD efektif dan memadai pada kondisi IKM kreatif. Konsep teknis dapat disaring dan dinilai menggunakan pugh selection matrix, tetapi setiap konsep teknis tidak dapat dideskripsikan ke dalam domain fungsi dan sarana yang lebih detail. Oleh karena itu dilakukan penambahan metode yang diterapkan secara paralel, yaitu dekomposisi konsep dengan function means tree, dan sintesa solusi teknis dengan axiomatic design agar proses desain lebih mudah ditangani. Rekomendasi yang diberikan adalah mengeliminasi proses zigzagging pada axiomatic design karena telah dilakukan pada function means tree, dan penggunaan data base customer relationship management untuk mendukung voice of customer.
\end{abstract}

Kata kunci: Daya saing; Dekomposisi fungsional; Industri kecil menengah; Pengembangan produk baru; Quality function deployment.

${ }^{*}$ Corresponding author: brotohartanto@gmail.com

Copyright (C) 2018 THE AUTHOR(S). This article is distributed under a Creative Commons Attribution-Share Alike 4.0 International license. 


\section{PENGANTAR}

\section{Industri Kecil Menengah dan Permasalahannya}

Industri di Indonesia didominasi oleh industri skala kecil dan menengah (IKM) atau sekitar $90 \%$ dari total industri, dengan salah satunya adalah sektor industri kreatif yang terdiri dari 16 sub-sektor berdasarkan Peraturan Presiden Nomor 72, 2015. Di Daerah Istimewa Yogyakarta, salah satu fokus pengembangan industri kreatif adalah pada sub-sektor fashion.

Pertumbuhan IKM di Indonesia tidak lepas dari berbagai kendala dan permasalahan yang harus dihadapi. Kendala pada IKM umumnya berkaitan dengan sumber daya manusia, pemasaran, sumber daya dan akses teknologi, dan inovasi. Permasalahan pengusaha kecil dan menengah di antaranya keterbatasan modal kerja dan/atau modal investasi, kesulitan mendapatkan bahan baku dengan kualitas baik dan harga terjangkau, keterbatasan teknologi, sumber daya manusia dengan kualitas yang baik, informasi pasar, dan kesulitan dalam pemasaran. Pada industri kreatif, kendala yang dihadapi diantaranya adalah terbatasnya akses kredit, akses ke pasar internasional, dan ketrampilan sumber daya manusia dalam berproduksi.

\section{Daya Saing Industri Kecil Menengah}

IKM membutuhkan peningkatan daya saing untuk dapat bertahan dan berkembang di pasar persaingan, salah satunya melalui pengembangan inovasi dan produk baru. Daya saing perusahaan dikatakan juga mengacu pada daya saing produk, efisiensi produksi, posisi keuangan, dan efektivitas organisasi dalam hal restrukturisasi dan stimulasi penjualan dan permintaan. Daya saing perusahaan tergantung pada kemampuannya untuk memproduksi produk dengan kualitas yang selalu meningkat, mengurangi biaya, dan time-to-market yang cepat. Perubahan kondisi ekonomi dan perkembangan teknologi meningkatkan persaingan pasar, perubahan kebutuhan konsumen, keusangan produk yang cepat, dan kemunculan pasar baru membutuhkan proses inovasi yang cepat. Proses pengembangan produk yang baik merupakan alat strategis perusahaan dalam menghadapi kompetisi pasar dengan cara menghasilkan produk dengan keunggulan kompetitif, dan dianggap sebagai salah satu kunci kesuksesan berbagai bisnis.

Pengembangan produk baru merupakan aktivitas yang kompleks dan dipengaruhi oleh kondisi internal dan eksternal perusahaan. Salah satu isu dalam pengembangan produk adalah ketepatan waktu dan kemampuan fleksibilitas untuk mempercepat proses pengembangan produk baru. Sedangkan kendala yang mempengaruhi kesuksesan pengembangan produk baru di IKM diantaranya adalah kurangnya akses terhadap sumber daya, kurangnya kontak eksternal, dan dipengaruhi oleh dominasi kepribadian dari pemilik maupun pimpinannya.

Berdasarkan hal tersebut, penting bagi IKM untuk memiliki kerangka kerja sebagai alat perencanaan pengembangan produk baru yang dapat mendukung kesuksesan produk di pasar. Penelitian ini bertujuan untuk diperolehnya kerangka kerja perencanaan sebagai alat untuk mendukung proses pengembangan produk baru yang efektif bagi peningkatan daya saing IKM.

\section{Penelitian Pengembangan Produk Baru di Industri Kecil Menengah}

Proses pengembangan produk baru memiliki peran signifikan bagi kesuksesan perusahaan. Proses pengembangan produk baru dengan cepat, efektif, dan efisien menjadi faktor signifikan dalam kesuksesan perusahaan. Pengembangan dan pengenalan produk baru berdasarkan kebutuhan konsumen menjadi kriteria penting bagi pertumbuhan dan kesuksesan perusahaan.

Salah satu pengembangan produk baru yang secara keseluruhan prosesnya dapat berdampak pada daya saing perusahaan adalah berdasarkan modular. Penerapan pengembangan produk berdasarkan modular menghasilkan waktu dan biaya yang rendah, sehingga dampak positif pada total aliran informasi dan material dari pengembangan, dan pembelian hingga ke penyimpanan dan pengiriman. 
Metode yang umum digunakan untuk pengembangan produk berdasarkan modular adalah Modular Function Deployment (MFD) oleh Gunnar Erixon tahun 1998. Desain produk modular mendasari pembaharuan produk berkelanjutan dan pengembangan simultan sistem produksi.

Pendekatan yang digunakan dalam rangkaian MFD diantaranya adalah quality function deployment (QFD), yaitu metode dalam pengembangan produk baru dan layanan yang dilakukan melalui proses sistematis terhadap pemahaman kebutuhan konsumen kedalam setiap aspek desain untuk meningkatkan kualitas dalam rangka memenuhi harapan konsumen. Pendekatan QFD umum digunakan untuk memahami dan menjelaskan keinginan konsumen dan karakteristik atau fitur teknis sebuah produk baru, serta QFD memberikan keuntungan bagi organisasi dan konsumennya, serta dapat digunakan untuk mengurangi biaya, membantu pengambilan keputusan, dan perbaikan kualitas.

Pemanfaatan QFD dapat secara fleksibel diterapkan pada berbagai jenis produk. Penerapan QFD dilakukan pada berbagai obyek produk barang, seperti kendaraan bermotor, perangkat elektronik, alat komunikasi mobile, perawatan kulit, dan produk fashion kreatif, serta diterapkan untuk analisis layanan, seperti pada layanan organisasi profesi, dan layanan universitas.

Pendekatan dekomposisi fungsional pada MFD menggunakan pugh selection matrix, di mana metode tersebut dapat efektif membandingkan antarkonsep dan menetapkan konsep yang "terbaik" dengan penerapan yang sederhana, meskipun memiliki kelemahan dalam penggunaan jam kerja. Pendekatan $p u g h$ selection matrix efektif diterapkan pada desain dan pengembangan berbagai produk, seperti mesin, dan alat elektronik.

Metode dekomposisi fungsional yang lain adalah function means tree, yang merupakan pendekatan sederhana yang dapat digunakan pada pemodelan fungsi teknis, dan semantik, meskipun memiliki beberapa kekurangan sehingga diperlukan pemodelan tambahan dan kombinasi pendekatan yang lain.
Selain itu terdapat metode axiomatic design, yang efektif digunakan untuk kasus perancangan produk baru beserta solusinya secara bersamaan pada beberapa system dan kebutuhan perusahaan, sehingga tetap dapat bersaing, dan bertindak cepat terhadap perubahan pasar serta pilihan konsumen.

\section{Metode}

Penelitian dilakukan di Daerah Istimewa Yogyakarta. Objek penelitian di industri kecil pada produsen sarung tangan olah raga AVELIO, dan industri menengah pada produsen tas bahan alam GENDHIS BAGS. Peralatan penelitian terdiri dari: kuesioner untuk menghimpun data (perusahaan dan pengguna produk), IBM SPSS versi 23 untuk uji data, dan Microsoft Excell 2011 untuk tabulasi dan analisis house of quality. Penelitian ini mengacu dari tahapan Design Science Research oleh William Kuechler dan Vijay Vaishnavi (2012), yang terdiri dari lima tahapan, seperti pada Gambar 1.

1. Tahapan Pertama: Awareness of Problem (Pernyataan Masalah)

Mendefinisikan permasalahan IKM di Yogyakarta, sehingga dapat diketahui pernyataan masalah yang diselesaikan melalui penelitian ini.

2. Tahapan Kedua: Suggestion (Studi Literatur) Membahas tentang teori dan penelitian terkait IKM, kasus sejenis, metode sejenis terdahulu, dan teori desain yang telah diterima secara umum.

3. Tahapan Ketiga: Development (Pembangunan Kerangka Kerja)

Diawali oleh persiapan pengumpulan data, pelaksanaan pengumpulan data dari responden, dan dilakukan pengujian data. Tahapan ini mengadaptasi 2 (dua) tahapan pertama dari keseluruhan (lima tahap) proses MFD. Tahapan pertama adalah deskripsi kebutuhan konsumen menggunakan QFD (fase perencanaan produk) melalui house of quality. Tahapan kedua adalah dekomposisi fungsional menggunakan metode pugh selection matrix. Dalam penelitian ini ditambahkan 
alternatif metode dekomposisi yang lain, yaitu axiomatic design, dan function and means tree.

4. Tahapan Keempat: Evaluation (Evaluasi Dekomposisi Fungsional)

Merupakan tahap evaluasi penggunaan ketiga metode dekomposisi fungsional terhadap analisis seleksi konsep teknis yang diimplementasikan di IKM. Hasil evaluasi dapat diketahui karakter dan peran dekomposisi fungsional yang berbeda-beda. Validitas pragmatis mem- pertimbangkan batasan dan kendala IKM. Pada tahapan ini diambil saran berupa penetapan penerapan metode dekomposisi yang efektif dan memuaskan untuk diterapkan pada IKM.

5. Tahapan Kelima: Conclusion (Kesimpulan dan Hasil Evaluasi)

Tahapan ini menetapkan langkah dekomposisi fungsional yang terbaik berdasarkan pertimbangan yang sesuai dan efektif diimplementasikan di IKM.

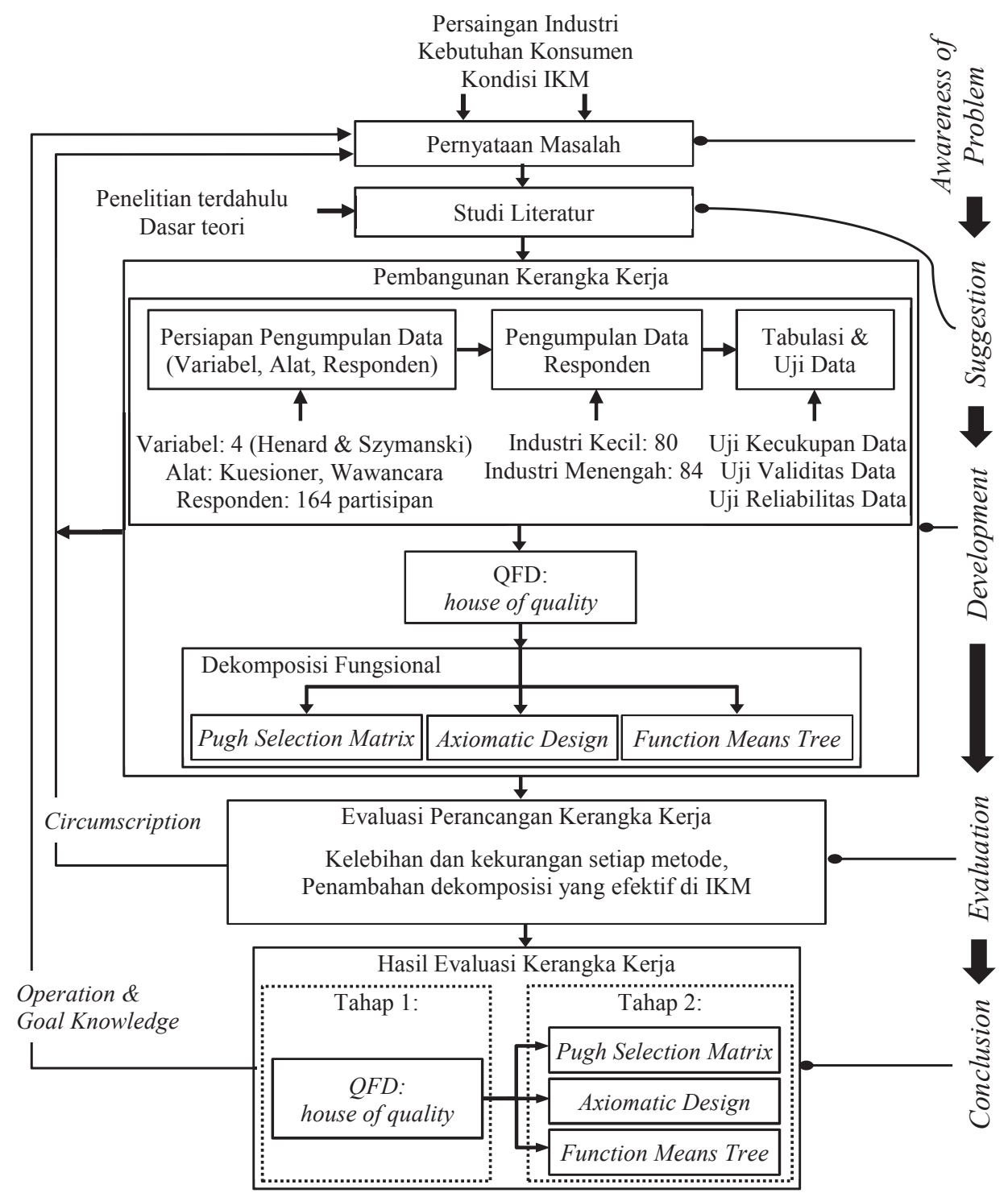

Gambar 1.

Tahapan Penelitian berdasarkan Design Science Research 


\section{HASIL DAN PEMBAHASAN}

Penelitian mengikuti urutan yang disusun berdasarkan tahapan design science research, meliputi:

\section{Awareness of Problem}

Tahapan ini mendefinisikan permasalahan yang ada di lingkungan IKM di Yogyakarta melalui obeservasi lapangan. Berdasarakan hasil observasi lapangan, dapat diketahui bahwa persaingan industri meningkat akibat pertumbuhan jumlah usaha IKM yang sangat signifikan, sehingga mempengaruhi kondisi internal perusahaan. Kondisi persaingan membuat IKM harus memiliki daya saing tersendiri, agar dapat bertahan dan memenangkan persaingan di pasar yang semakin dinamis. Daya saing IKM dapat dicapai melalui sektor produk yang mampu memenuhi kebutuhan dan keinginan konsumen. Berdasarkan latar belakang masalah, dapat diketahui pentingnya menciptakan daya saing industri untuk bertahan di persaingan usaha, yaitu melalui pengembangan produk baru. Sehingga penting bagi IKM di DIY memiliki sebuah kerangka kerja perencanaan sebagai tools pengembangan produk yang dapat mendukung kesuksesan produk baru sebagai daya saing IKM di pasar persaingan.

\section{Suggestion}

Tahapan ini berfungsi mencari berbagai sumber informasi terkait bagaimana permasalahan IKM diselesaikan, cara mencapai tujuan dari penelitian, dan informasi berupa data sekunder untuk menunjang dan memastikan bahwa penelitian dan tujuan penyelesaian permasalahan yang ada di IKM dapat diselesaikan. Tahapan ini melakukan pengumpulan data sekunder dari buku, data publik dari berbagai sumber resmi di situs web, penelitian sejenis terdahulu yang ada di jurnal, studi pustaka baik melalui sumber buku maupun sumber informasi dari internet terkait teori-teori yang berkaitan dengan permasalahan dan cara penyelesaian, dan pemahaman pada variabel, indikator maupun metode yang digunakan untuk menyelesaikan permasalahan penelitian. Pada tahapan suggestion dihasikan kerangka penelitian yang terdiri dari penetapan variabel, indikator, dan metode penyelesaian beserta penerapannya.

\section{Development}

Tahapan ini adalah bagian proses pembangunan kerangka kerja, di mana merupakan tahapan ketiga dalam design science research. Tahapan ini menjelaskan proses pembangunan kerangka kerja perencanaan pengembangan produk baru di IKM sektor kreatif. Analisis dan pengembangan mengikuti urutan seperti pada Gambar 2.

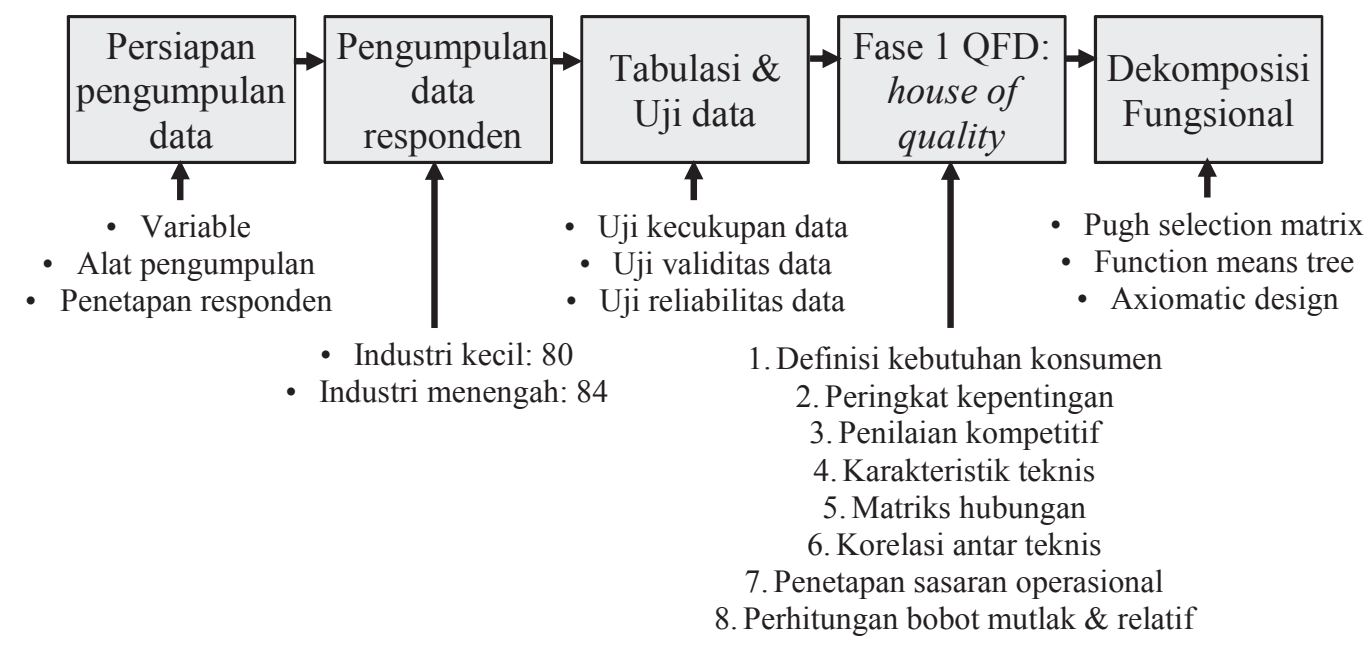

Gambar 2.

Langkah Analisis dan Pembangunan Kerangka Kerja 


\section{Bagian Pertama: Persiapan Pengumpulan Data}

Terdiri dari kegiatan penetapan variabel, penyusunan alat pengumpulan data (kuesioner dan wawancara), dan penetapan responden. Variabel penelitian mengacu pada studi oleh
Henard dan Szymanski (2001), sedangkan indikator konsekuensi dari setiap variabel mengacu kepada 23 indikator dari Cooper (1979), yang kemudian dikelola dalam affinity diagram, seperti pada Tabel 1.

Tabel 1. Variabel dan Indikator Penelitian

\begin{tabular}{|c|c|c|}
\hline Variabel & No. & Indikator (konsekuensi) \\
\hline \multirow{5}{*}{ Karakteristik Produk } & 1.1 & Keunggulan produk \\
\hline & 1.2 & Produk memenuhi kebutuhan konsumen \\
\hline & 1.3 & Harga produk \\
\hline & 1.4 & Kecanggihan teknologi produk \\
\hline & 1.5 & Inovasi produk \\
\hline \multirow{5}{*}{ Karakteristik Strategi Perusahaan } & 2.1 & Sinergi pemasaran \\
\hline & 2.2 & Sinergi teknologi \\
\hline & 2.3 & Order of entry \\
\hline & 2.4 & Komitmen SDM \\
\hline & 2.5 & Komitmen sumber daya R\&D \\
\hline \multirow{11}{*}{ Karakteristik Proses Perusahaan } & 3.1 & Pendekatan terstruktur \\
\hline & 3.2 & Kemahiran aktifitas predevelopment \\
\hline & 3.3 & Kemahiran tugas pemasaran \\
\hline & 3.4 & Kemahiran teknologi \\
\hline & 3.5 & Kemahiran peluncuran produk baru \\
\hline & 3.6 & Mengurangi cycle time \\
\hline & 3.7 & Orientasi pasar \\
\hline & 3.8 & Input konsumen \\
\hline & 3.9 & Integrasi lintas fungsi \\
\hline & 3.10 & Komunikasi lintas fungsi \\
\hline & 3.11 & Dukungan manajemen senior \\
\hline \multirow{2}{*}{ Karakteristik Pasar } & 4.1 & Tingkatan respon persaingan \\
\hline & 4.2 & Pasar potensial \\
\hline
\end{tabular}

\section{Bagian Kedua: Pengumpulan Data Responden}

Data primer dari perusahaan dikumpulkan dengan cara brainstorming dan wawancara. Sedangkan data primer dari responden eksternal dihimpun melalui kuesioner, yang dilakukan dari September-Desember 2017, dengan teknik sampling nonprobabilitas jenis purposive sampling kepada 80 partisipan untuk industri kecil dan 84 partisipan untuk industri menengah. Jumlah data primer mengikuti metode dari Griffin dan Hauser (1993), yang menyatakan bahwa estimasi 90\% kebutuhan konsumen pada produk dapat diketahui setelah melakukan 30 wawancara. Selain itu berdasarkan metode dari Hair, dkk (2009), yang merekomendasikan rasio 10:1 atau 20:1 untuk setiap variabel yang dipakai dalam penelitian. Responden merupakan orang dengan pengalaman dan/atau mengetahui produk dari setiap industri.

\section{BAGIAN KETIGA: TABULASI DAN UJI DATA}

Tabulasi data menggunakan Microsoft Excel 2011, untuk kemudian dilakukan pengujian data, yang terdiri dari uji kecukupan data, uji validitas data, dan uji reliabilitas data. 
Hasil pengujian menyatakan bahwa semua data yang dikumpulkan telah cukup secara objektif sejumlah 164, dan berdasarkan uji dengan IBM SPSS v.23 seluruh data dinyatakan valid dan reliabel, dan dapat digunakan untuk analisis selanjutnya.

\section{Bagian Keempat: Implementasi Quality Function Deployment (QFD)}

Penerapan fase pertama dari empat fase QFD, dilakukan dengan pembangunan 8 (delapan) langkah house of quality $(\mathrm{HoQ})$, seperti pada Gambar 3, yaitu:

1. Langkah pertama: penetapan definisi kebutuhan konsumen (WHATs),

2. Langkah kedua: penilaian peringkat kepentingan kebutuhan konsumen,

3. Langkah ketiga: penilaian kompetitif dengan produk dan perusahaan pesaing untuk mengetahui rasio perbaikan yang harus dilakukan perusahaan,

4. Langkah keempat: pembangunan karakteristik (fitur) teknis (HOWs),

5. Langkah kelima: melakukan analisis hubungan fitur teknis dengan kebutuhan konsumen (WHATs vs HOWs) yang dikelola menjadi matriks hubungan,

6. Langkah keenam: melakukan analisis korelasi antar fitur teknis,

7. Langkah ketujuh: menetapkan sasaran operasional oleh perusahaan yang menerangkan upaya perusahaan yang harus diambil untuk memenuhi kebutuhan konsumen,

8. Langkah kedelapan: menghitung bobot mutlak dan relatif, untuk mengetahui prioritas karakteristik teknis berdasarkan konsumen, kompetitor dan internal perusahaan.

\begin{tabular}{|c|c|c|c|c|c|c|c|c|c|c|c|c|c|c|}
\hline & & \multirow{2}{*}{ 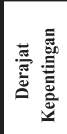 } & \multirow{2}{*}{ 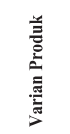 } & \multirow{2}{*}{ 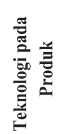 } & \multirow{2}{*}{ 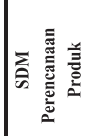 } & \multirow{2}{*}{ 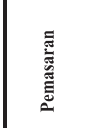 } & \multirow{2}{*}{ 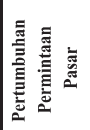 } & \multicolumn{4}{|c|}{ Kompetitif } & \multirow{2}{*}{$\begin{array}{c}\text { Nilai } \\
\text { Target }\end{array}$} & \multirow{2}{*}{$\begin{array}{c}\text { Scale- } \\
U p \\
\text { Factor }\end{array}$} & \multirow[b]{2}{*}{$\begin{array}{c}\text { Raw } \\
\text { Weight }\end{array}$} \\
\hline & & & & & & & & Avelio & Fox & pecialized & Lainnya & & & \\
\hline 1.1 & Kcunggulan produk & 4,33 & 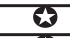 & $\odot$ & & & $\odot$ & 3,6 & 3,2 & 3,4 & 3,4 & 5 & 1,39 & 6,02 \\
\hline 1.2 & Produk memenuhi kebutuhan konsumen & 4,45 & $\star$ & $\odot$ & 0 & $\odot$ & $\star$ & 3,7 & 3,3 & 3,4 & 3,3 & 5 & 1,35 & 6,01 \\
\hline 1.3 & Harga produk & 4,40 & 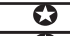 & 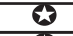 & & & & 3,6 & 3,2 & 3,3 & 3,3 & 5 & 1,39 & 6,12 \\
\hline 1.4 & Kecanggihan teknologi produk & 3,95 & $\star$ & 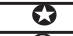 & 0 & & & 3,6 & 3,2 & 3,3 & 3,1 & 5 & 1,39 & 5,49 \\
\hline 1.5 & Inovasi produk & 4,10 & 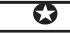 & $\odot$ & & $\odot$ & & 3,9 & 3,4 & 3,5 & 3,3 & 5 & 1,28 & 5,25 \\
\hline 2.1 & Sinergi pemasaran & 4,13 & & & & $\odot$ & 0 & 3,4 & 3,3 & 3,3 & 3,2 & 5 & 1,47 & 6,07 \\
\hline 2.2 & Sinergi teknologi & 4,11 & & $\odot$ & 0 & 0 & & 3,4 & 3,4 & 3,4 & 3,3 & 5 & 1,47 & 6,04 \\
\hline 2.3 & Order of entry & 3,53 & & & $\odot$ & $\Delta$ & & 3,3 & 3 & 3 & 2,9 & 5 & 1,52 & 5,37 \\
\hline 2.4 & Komitmen SDM & 3,85 & 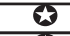 & 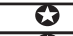 & 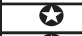 & $\odot$ & & 3,4 & 3,1 & 3,2 & 3,1 & 5 & 1,47 & 5,66 \\
\hline 2.5 & Komitmen sumber daya R\&D & 4,36 & $\star$ & 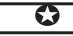 & 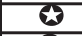 & $\odot$ & $\odot$ & 3,5 & 3,4 & 3,5 & 3,3 & 5 & 1,43 & 6,23 \\
\hline 3.1 & $\begin{array}{l}\text { Pendekatan terstruktur } \\
\end{array}$ & 3,46 & & & 0 & & & 3,3 & 3 & 3 & 3 & 5 & 1,52 & 5,26 \\
\hline 3.2 & \begin{tabular}{|ll} 
Kemahiran aktifitas & predevelopment
\end{tabular} & 4,09 & $\odot$ & $\odot$ & $\odot$ & $\star$ & $\odot$ & 3,5 & 3,2 & 3,3 & 3,2 & 5 & 1,43 & 5,85 \\
\hline 3.3 & Kemahiran tugas pemasaran & 4,65 & & & & 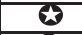 & $\odot$ & 3,7 & 3,5 & 3,5 & 3,3 & 5 & 1,35 & 6,28 \\
\hline 3.4 & Kemahiran teknologi & 4,13 & & 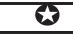 & $\odot$ & $\odot$ & & 3,5 & 3,3 & 3,4 & 3,2 & 5 & 1,43 & 5,91 \\
\hline 3.5 & Kemahiran peluncuran produk baru & 3,70 & & & 0 & 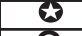 & & 3,4 & 3,1 & 3,2 & 3,1 & 5 & 1,47 & 5,44 \\
\hline 3.6 & Mengurangi cycle time & 3,49 & & & 0 & O & & 3,3 & 3 & 3,1 & 3 & 5 & 1,52 & 5,30 \\
\hline 3.7 & Orientasi pasar & 4,06 & 0 & 0 & $\odot$ & $\odot$ & $\odot$ & 3,4 & 3,2 & 3,2 & 3,2 & 5 & 1,47 & 5,97 \\
\hline 3.8 & Input konsumen & 4,11 & & & 0 & $\odot$ & 0 & 3,5 & 3,2 & 3,2 & 3,2 & 5 & 1,43 & 5,88 \\
\hline 3.9 & Integrasi lintas fungsi & 3,69 & 0 & 0 & 0 & 0 & & 3,3 & 3 & 3,1 & 3 & 5 & 1,52 & 5,61 \\
\hline 3.10 & Komunikasi lintas fungsi & 3,41 & & & & 0 & & 3,3 & 2,9 & 3 & 3 & 5 & 1,52 & 5,18 \\
\hline 3.11 & Dukungan manajemen senior & 3,80 & 0 & 0 & 0 & $\Delta$ & $\odot$ & 3,4 & 3 & 3,1 & 3 & 5 & 1,47 & 5,59 \\
\hline 4.1 & Tingkatan respon persaingan & 3,78 & & & 0 & 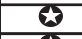 & 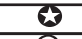 & 3,4 & 3,1 & 3,3 & 3,1 & 5 & 1,47 & 5,56 \\
\hline 4.2 & Pasar potensial & 4,03 & 0 & 0 & $\odot$ & 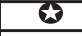 & $\odot$ & 3,5 & 3,2 & 3,4 & 3,3 & 5 & 1,43 & 5,76 \\
\hline & Sasaran & ional & P.1. & P.1. & St.1. & Pr.1. & M.1. & & & & & & & \\
\hline & ВОВОт 1 & $\mathbf{K}(\mathbf{B m})$ & 292,81 & 265,03 & 171,95 & 362,49 & 170,27 & & & & & & & \\
\hline & ВОВОт & IIF (Br) & 407,45 & 375,08 & 273,27 & 521,58 & 241,12 & & & & & & & \\
\hline
\end{tabular}

Gambar 3.

House of Quality Pada Industri Kecil 
Analisis HoQ pada industri kecil menghasilkan 5 (lima) karakteristik (konsep) teknis, yaitu pemasaran, varian produk, teknologi pada produk, sumber daya manusia bagian perencanaan produk, dan pertumbuhan permintaan pasar. Pada industri menengah menghasilkan 7 (tujuh) karakteristik teknis, yaitu pembentukan departemen pengembang produk dan tim, pemasaran, peningkatan desain, harga, segmen pasar baru, bahan baku, dan database desain produk beserta SOP.

\section{Bagian Kelima: Dekomposisi Fungsional}

Identifikasi dari beberapa fungsi dan sub-fungsi sebuah konsep teknis dengan mempertimbangkan internal perusahaan. Pendekatan yang digunakan Pugh Selection Matrix, Function Means Tree, dan Axiomatic Design, yang dilakukan secara paralel. Metode pugh selection matrix, terdiri dari penyaringan dan penilaian konsep, seperti pada Tabel 2.

Tabel 2. Penyaringan dan Penilaian Konsep Teknis Pada Industri Menengah

\begin{tabular}{|c|c|c|c|c|c|c|c|c|}
\hline & & 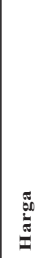 & 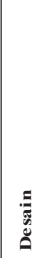 & 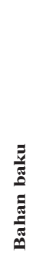 & 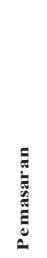 & 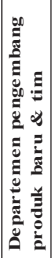 & 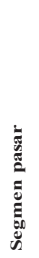 & 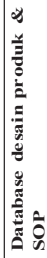 \\
\hline \multicolumn{2}{|r|}{ KODE } & A & B & $\mathrm{C}$ & D & E & $\mathrm{F}$ & G \\
\hline & Keunggulan produk & \begin{tabular}{|l|l}
0 \\
\end{tabular} & ++ & + & + & + & + & + \\
\hline 1.2 & Produk memenuhi kebutuhan konsumen & \begin{tabular}{|c|ccc}
+ \\
\end{tabular} & + & 0 & ++ & 0 & + & 0 \\
\hline 1.3 & Harga produk & \begin{tabular}{|l|l}
0 \\
\end{tabular} & + & + & 0 & 0 & + & 0 \\
\hline 1.4 & Kecanggihan teknologi produk & - & 0 & + & 0 & 0 & + & 0 \\
\hline 1.5 & Inovasi produk & \begin{tabular}{|l|l}
0 \\
\end{tabular} & ++ & + & 0 & + & 0 & + \\
\hline 2.1 & Sinergi pemasaran & - & 0 & 0 & + & 0 & + & 0 \\
\hline 2.2 & Sinergi teknologi & 0 & 0 & 0 & + & + & 0 & 0 \\
\hline 2.3 & Order of entry & \begin{tabular}{|l|l}
0 \\
\end{tabular} & 0 & 0 & + & 0 & 0 & 0 \\
\hline 2.4 & Komitmen SDM & \begin{tabular}{|l|l}
0 \\
\end{tabular} & ++ & 0 & ++ & 0 & 0 & 0 \\
\hline 2.5 & Komitmen sumber daya $R \& D$ & 0 & 0 & 0 & 0 & + & + & 0 \\
\hline 3.1 & \begin{tabular}{|l} 
Pendekatan terstruktur \\
\end{tabular} & 0 & 0 & 0 & 0 & 0 & 0 & + \\
\hline 3.2 & Kemahiran aktifitias predevelopment & \begin{tabular}{|l|l}
0 \\
\end{tabular} & + & 0 & 0 & + & 0 & + \\
\hline 3.3 & Kemahiran tugas pemasaran & \begin{tabular}{|l|l}
0 \\
\end{tabular} & 0 & 0 & + & 0 & + & 0 \\
\hline 3.4 & Kemahiran teknologi & 0 & + & 0 & 0 & 0 & 0 & + \\
\hline 3.5 & Kemahiran peluncuran produk baru & \begin{tabular}{|l|l}
0 \\
\end{tabular} & 0 & 0 & 0 & + & 0 & 0 \\
\hline 3.6 & \begin{tabular}{|l} 
Mengurangi cycle time \\
\end{tabular} & \begin{tabular}{|l|l}
0 \\
\end{tabular} & 0 & 0 & + & + & 0 & + \\
\hline 3.7 & \begin{tabular}{|l|} 
Orientasi pasar \\
\end{tabular} & \begin{tabular}{|l|l}
0 \\
\end{tabular} & 0 & 0 & + & + & + & + \\
\hline 3.8 & Input konsumen & - & + & 0 & 0 & + & 0 & + \\
\hline 3.9 & Integrasi lintas fungsi & \begin{tabular}{|l|l}
0 \\
\end{tabular} & 0 & 0 & + & 0 & 0 & + \\
\hline 3.10 & Komunikasi lintas fungsi & \begin{tabular}{|l|l}
0 \\
\end{tabular} & 0 & 0 & 0 & 0 & 0 & 0 \\
\hline 3.11 & Dukungan manajemen senior & \begin{tabular}{|l|l}
0 \\
\end{tabular} & + & 0 & + & + & 0 & 0 \\
\hline 4.1 & Tingkatan respon persaingan & 0 & + & 0 & 0 & + & 0 & 0 \\
\hline \multirow[t]{6}{*}{4.2} & \begin{tabular}{|l|} 
Pasar potensial \\
\end{tabular} & 0 & 0 & + & 0 & + & + & + \\
\hline & Positif (+) & 1 & 10 & 5 & 11 & 12 & 9 & 10 \\
\hline & Sama (0) & 19 & 13 & 18 & 12 & 11 & 14 & 13 \\
\hline & Negatif $(-)$ & 3 & 0 & 0 & 0 & 0 & 0 & 0 \\
\hline & Total Point & \begin{tabular}{|l|}
-2 \\
\end{tabular} & 10 & 5 & 11 & \begin{tabular}{|l|}
12 \\
\end{tabular} & 9 & 10 \\
\hline & Rangking & \begin{tabular}{|l|}
6 \\
\end{tabular} & 3 & 5 & 2 & 1 & 4 & 3 \\
\hline
\end{tabular}

Pada industri kecil dapat diketahui prioritas konsep teknis tertinggi adalah pemasaran, kemudian peningkatan SDM perencanaan produk baru, peningkatan varian produk, penerapan teknologi pada produk, dan terendah adalah strategi pertumbuhan permintaan pasar. Pada industri menengah,

\begin{tabular}{|c|c|c|c|c|c|c|c|}
\hline & & E & D & B & $\mathrm{F}$ & G & C \\
\hline Indika & bot & g WS R & $\operatorname{Rtg} \mid$ WS & $\operatorname{Rtg}$ WS R & Rtg | WS R R & $\operatorname{Rtg}$ WS R R & $\operatorname{Rtg}$ WS \\
\hline Keunggulan produk & $6 \%$ & \begin{tabular}{|l|l|}
5 & 0.3 \\
\end{tabular} & \begin{tabular}{|l|l|}
4 & 0.24 \\
\end{tabular} & \begin{tabular}{|l|l|l|}
5 & 0.3 & 4 \\
\end{tabular} & \begin{tabular}{|l|l|}
4 & 0.24 \\
\end{tabular} & \begin{tabular}{|l|l|}
4 & 0.24
\end{tabular} & \begin{tabular}{|l|l|}
5 & 0.3 \\
\end{tabular} \\
\hline Produk memenuhi kebutuha & $4 \%$ & \begin{tabular}{|l|l|}
5 & 0.2 \\
\end{tabular} & \begin{tabular}{|l|l|}
4 & 0.16 \\
\end{tabular} & \begin{tabular}{|l|l|l|}
5 & 0.2 & 4 \\
\end{tabular} & \begin{tabular}{|l|l|}
4 & 0.16 \\
\end{tabular} & \begin{tabular}{|l|l|}
4 & 0.16 \\
\end{tabular} & \begin{tabular}{|l|l|}
5 & 0.2 \\
\end{tabular} \\
\hline Harga produk & $5 \%$ & 50.25 & \begin{tabular}{|l|l|}
4 & 0.2 \\
\end{tabular} & \begin{tabular}{ll|l|l|} 
& 0.25 & 4 \\
\end{tabular} & \begin{tabular}{|l|l|}
4 & 0.2 \\
\end{tabular} & \begin{tabular}{|l|l|}
4 & 0.2 \\
\end{tabular} & 50.25 \\
\hline Kecanggihan tekno & $3 \%$ & \begin{tabular}{|l|l|}
5 & 0.15 \\
\end{tabular} & \begin{tabular}{|l|l|}
4 & 0.12 \\
\end{tabular} & \begin{tabular}{|l|l|l|l|}
4 & 0.12 & 4 \\
\end{tabular} & \begin{tabular}{|l|l|l|}
4 & 0.12 \\
\end{tabular} & \begin{tabular}{lll|}
4 & 0.12 \\
\end{tabular} & 40.12 \\
\hline \begin{tabular}{|l|} 
Inovasi produk \\
\end{tabular} & $7 \%$ & 50.35 & \begin{tabular}{|l|l|}
4 & 0.28 \\
\end{tabular} & 50.355 & \begin{tabular}{|l|l|}
5 & 0.35 \\
\end{tabular} & $\begin{array}{lll}4 & 0.28 \\
\end{array}$ & 50.35 \\
\hline Sinergi pemasaran & $3 \%$ D & \begin{tabular}{|l|l|}
30.09 \\
\end{tabular} & \begin{tabular}{|l|l|}
5 & 0.15 \\
\end{tabular} & \begin{tabular}{|l|l|l|l}
4 & 0.12 & 5 \\
\end{tabular} & \begin{tabular}{|l|l|}
5 & 0.15 \\
\end{tabular} & $\begin{array}{lll}3 & 0.09 \\
\end{array}$ & 30.09 \\
\hline Sinergi teknologi & $3 \%$ & $\begin{array}{lll}4 & 0.12 \\
\end{array}$ & \begin{tabular}{|l|l|}
5 & 0.15 \\
\end{tabular} & 50.154 & \begin{tabular}{|l|l|}
4 & 0.12 \\
\end{tabular} & $\begin{array}{lll}3 & 0.09 \\
\end{array}$ & 40.12 \\
\hline Order of entry & $3 \%$ & $\begin{array}{lll} & 0.12 \\
\end{array}$ & \begin{tabular}{|l|l|}
3 & 0.09 \\
\end{tabular} & \begin{tabular}{l|l|l|l|}
4 & 0.125 \\
\end{tabular} & \begin{tabular}{|l|l:}
5 & 0.15 \\
\end{tabular} & \begin{tabular}{|lll}
5 & 0.15 \\
\end{tabular} & 30.09 \\
\hline Komitmen SDM & $5 \%$ & \begin{tabular}{|l|l|}
4 & 0.2 \\
\end{tabular} & \begin{tabular}{|l|l|}
4 & 0.2 \\
\end{tabular} & \begin{tabular}{|l|l|l|}
4 & 0.2 & 3 \\
\end{tabular} & \begin{tabular}{|l|l|}
3 & 0.15 \\
\end{tabular} & \begin{tabular}{|l|l|}
4 & 0.2 \\
\end{tabular} & \begin{tabular}{|l|l|}
4 & 0.2 \\
\end{tabular} \\
\hline Komitmen sumber daya R\&D & $6 \%$ & \begin{tabular}{|l|l|}
5 & 0.3 \\
\end{tabular} & \begin{tabular}{|l|l|}
4 & 0.24 \\
\end{tabular} & \begin{tabular}{|l|l|l|}
5 & 0.3 & 3 \\
\end{tabular} & \begin{tabular}{|l|l:}
3 & 0.18
\end{tabular} & \begin{tabular}{|l|l|}
5 & 0.3 \\
\end{tabular} & \begin{tabular}{l|l|l}
4 & 0.24 \\
\end{tabular} \\
\hline Pendekatan terstruktur & $5 \%$ & 50.25 & \begin{tabular}{|l|l|}
5 & 0.25 \\
\end{tabular} & \begin{tabular}{l|l|l|l}
5 & 0.25 & 3 \\
\end{tabular} & \begin{tabular}{|l|l:}
3 & 0.15 \\
\end{tabular} & $\begin{array}{lll}5 & 0.25 \\
\end{array}$ & 30.15 \\
\hline Kemahiran aktifitas predevelopment & $3 \%$ & 50.15 & \begin{tabular}{|l|l|}
5 & 0.15 \\
\end{tabular} & \begin{tabular}{|l|l|l|l|}
4 & 0.12 & 4 \\
\end{tabular} & \begin{tabular}{|l|l|l|}
4 & 0.12 \\
\end{tabular} & \begin{tabular}{lll|}
4 & 0.12 \\
\end{tabular} & 40.12 \\
\hline Kemahiran tugas pemasaran & $6 \%$ & \begin{tabular}{|l|l|}
3 & 0.18 \\
\end{tabular} & \begin{tabular}{|l|l|}
5 & 0.3 \\
\end{tabular} & 30.185 & \begin{tabular}{|l|l|}
5 & 0.3 \\
\end{tabular} & \begin{tabular}{|l|l|}
3 & 0.18 \\
\end{tabular} & 30.18 \\
\hline Kemahiran teknologi & $3 \%$ & \begin{tabular}{|l|l|}
4 & 0.12 \\
\end{tabular} & \begin{tabular}{|l|l|}
4 & 0.12 \\
\end{tabular} & 40.124 & \begin{tabular}{|l|l|l|}
4 & 0.12 \\
\end{tabular} & \begin{tabular}{|l|l|}
4 & 0.12 \\
\end{tabular} & $\begin{array}{lll}40.12 \\
\end{array}$ \\
\hline Kemahiran peluncuran produk baru & $3 \%$ & 50.15 & \begin{tabular}{|l|l|}
5 & 0.15 \\
\end{tabular} & 300.095 & \begin{tabular}{|l|l:}
5 & 0.15 \\
\end{tabular} & $\begin{array}{lll} & 0.09 \\
\end{array}$ & 30.09 \\
\hline \begin{tabular}{|l|} 
Mengurangi cycle time \\
\end{tabular} & $5 \%$ & \begin{tabular}{|l|l|}
5 & 0.25 \\
\end{tabular} & \begin{tabular}{|l|l|}
5 & 0.25 \\
\end{tabular} & \begin{tabular}{l|l|l|}
4 & 0.2 & 5 \\
\end{tabular} & \begin{tabular}{|l|l|}
5 & 0.25 \\
\end{tabular} & \begin{tabular}{|l|l|}
4 & 0.2 \\
\end{tabular} & 30.15 \\
\hline Orientasi pasar & $3 \%$ & 50.15 & \begin{tabular}{|l|l|}
5 & 0.15 \\
\end{tabular} & 50.155 & \begin{tabular}{|l|l|}
5 & 0.15 \\
\end{tabular} & \begin{tabular}{|l|l|l|}
4 & 0.12 \\
\end{tabular} & \begin{tabular}{l|l|l|l|}
4 & 0.12 \\
\end{tabular} \\
\hline Input konsumen & $4 \%$ & \begin{tabular}{|l|l|}
5 & 0.2 \\
\end{tabular} & \begin{tabular}{|l|l|}
5 & 0.2 \\
\end{tabular} & \begin{tabular}{l|l|l}
5 & 0.2 & 5 \\
\end{tabular} & \begin{tabular}{|l|l|}
5 & 0.2 \\
\end{tabular} & \begin{tabular}{|l|l|}
5 & 0.2 \\
\end{tabular} & $\begin{array}{lll}40.16 \\
\end{array}$ \\
\hline Integrasi lintas fungsi & $4 \%$ & $\begin{array}{lll}40.16 \\
\end{array}$ & \begin{tabular}{|l|l|}
3 & 0.12 \\
\end{tabular} & \begin{tabular}{|l|l|l|l}
5 & 0.2 & 3 \\
\end{tabular} & \begin{tabular}{|l|l|}
3 & 0.12 \\
\end{tabular} & \begin{tabular}{|l|l|}
4 & 0.16 \\
\end{tabular} & 30.12 \\
\hline Komunikasi lintas fungsi & $3 \%$ & 30.09 & \begin{tabular}{|l|l|}
3 & 0.9 \\
\end{tabular} & 40.123 & \begin{tabular}{|l|l|}
3 & 0.09 \\
\end{tabular} & \begin{tabular}{|l|l|l|}
3 & 0.09 \\
\end{tabular} & 30.09 \\
\hline Dukungan manajemen senior & $6 \%$ & $\begin{array}{lll}3 & 0.18 \\
\end{array}$ & \begin{tabular}{|l|l|}
4 & 0.24 \\
\end{tabular} & \begin{tabular}{l|l|l}
5 & 0.3 & 4
\end{tabular} & \begin{tabular}{l|l|l}
4 & 0.24
\end{tabular} & \begin{tabular}{|l|l|}
3 & 0.18 \\
\end{tabular} & \begin{tabular}{l|l|l|l}
4 & 0.24
\end{tabular} \\
\hline Tingkatan respon persaingan & $4 \%$ & \begin{tabular}{|l|l|}
4 & 0.16 \\
\end{tabular} & \begin{tabular}{|l|l|}
5 & 0.2 \\
\end{tabular} & 40.165 & \begin{tabular}{|l|l|}
5 & 0.2 \\
\end{tabular} & \begin{tabular}{|l|l|}
4 & 0.16 \\
\end{tabular} & 40.16 \\
\hline Pasar potensial & $6 \%$ & \begin{tabular}{|l|l|}
4 & 0.24 \\
\end{tabular} & \begin{tabular}{|l|l|}
4 & 0.24 \\
\end{tabular} & 40.245 & \begin{tabular}{|l|l|}
5 & 0.3 \\
\end{tabular} & \begin{tabular}{|l|l|}
3 & 0.18 \\
\end{tabular} & 30.18 \\
\hline & L SCORE & 4.36 & 4.29 & 4.44 & 4.21 & 3.88 & 3.84 \\
\hline & KKING & 2 & 3 & 1 & 3 & 4 & 4 \\
\hline & UTUSAN & Ya & Ya & Ya & Ya & Ya & Ya \\
\hline
\end{tabular}

konsep tertinggi adalah peningkatan desain, pembentukan departemen pengembang produk baru dan tim, gabungan konsep (pemasaran dan segmen pasar), dan gabungan konsep database desain produk beserta SOP, dan bahan baku. 
Pada implementasi metode pugh selection matrix dapat diketahui bahwa metode tersebut dapat secara efektif menyaring dan menilai setiap konsep yang dihasilkan, sehingga IKM dapat mengetahui prioritas dari penerapan konsep teknis untuk memenuhi kebutuhan dan meningkatkan kepuasan konsumen.

Penerapan konsep teknis yang lebih efektif dan efisien oleh IKM membutuhkan informasi pada domain fungsi dan sarana. Terkait hal tesebut, metode pugh selection matrix memiliki batasan, di mana tidak dapat efektif mendeskripsikan kebutuhan konsep teknis tersebut kedalam domain fungsi serta sarana dengan lebih lengkap dan detail.

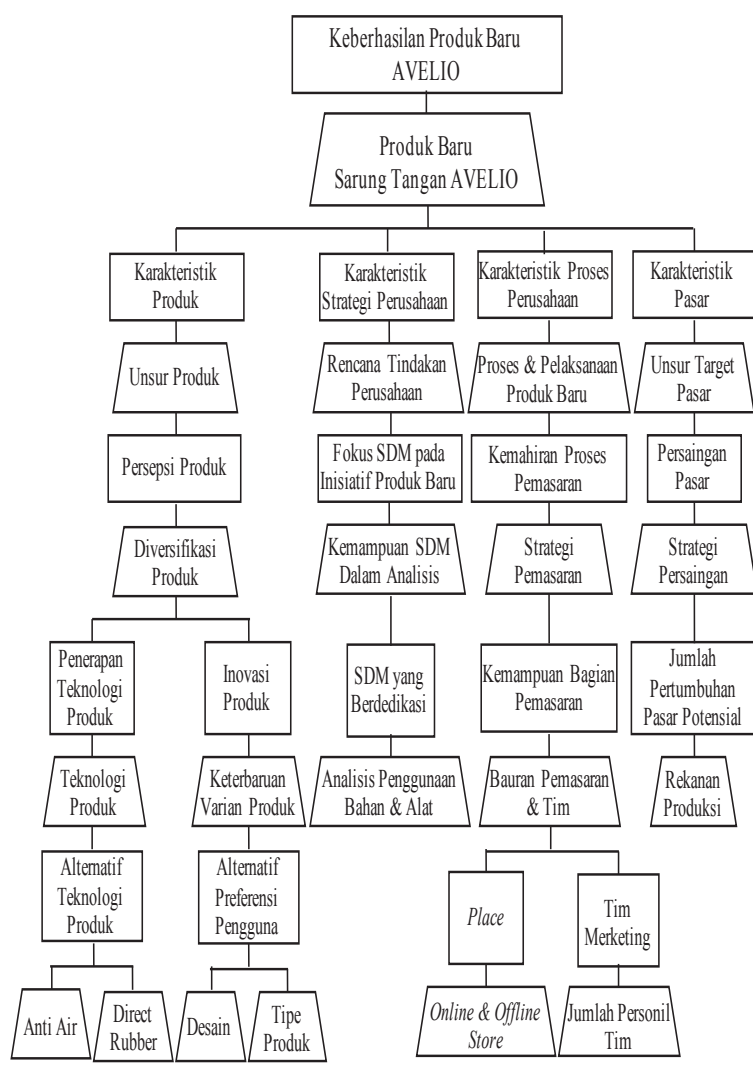

Dengan adanya batasan metode, serta mempertimbangkan kendala di IKM yaitu permodalan dan keterbatasan SDM membuat pelaksanaan konsep teknis menjadi sulit ditangani. Mengatasi hal tersebut maka pada penelitian ini tahap dekomposisi fungsional didukung dengan metode tambahan yang dilakukan secara paralel, yaitu function and means tree dan axiomatic design.

Pada analisis dengan function means tree menghasilkan 5 (lima) tingkatan (level) dengan fungsi dan elemen solusi atau sarana (means) yang saling berpasangan, yang ditunjukkan pada Gambar 4.

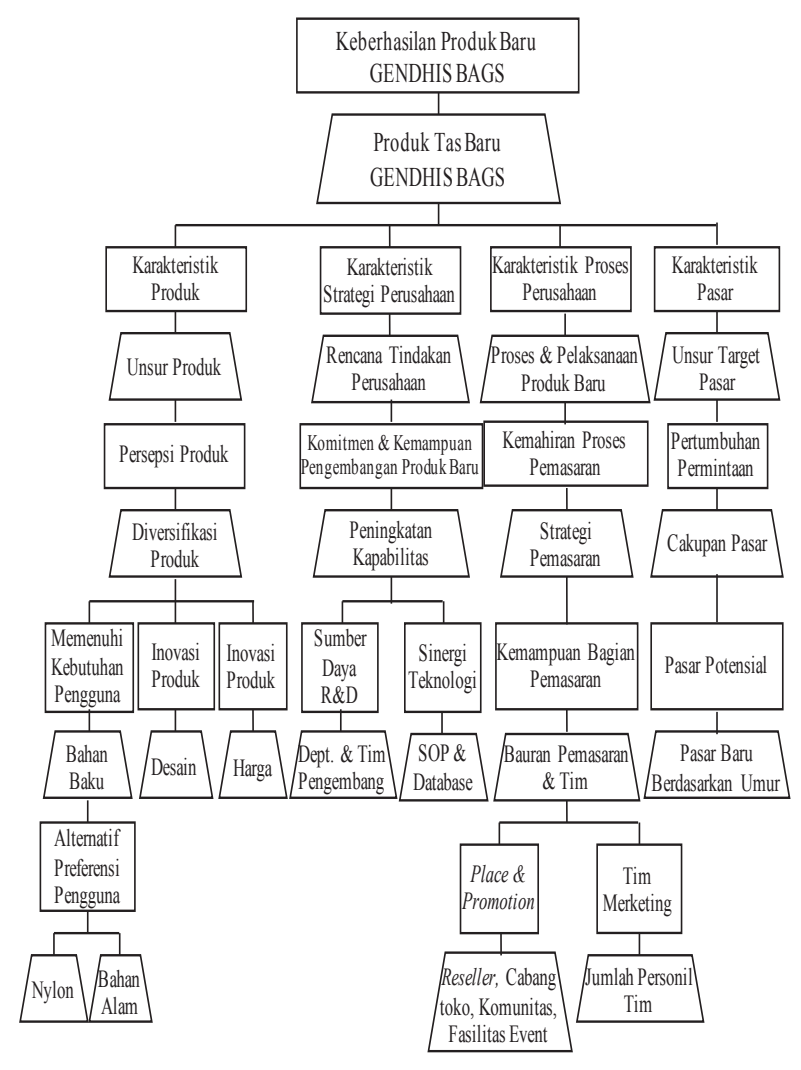

Gambar 4.

Function Means Tree Industri Kecil dan Menengah

Berdasarkan hasil analisis dapat ditunjukkan bahwa pada industri kecil menghasilkan 18 fungsi dan 20 sarana, sedangkan pada industri menengah menghasilkan 19 fungsi beserta 20 sarana yang dapat diterapkan untuk memenuhi kebutuhan dan kepuasan konsumen.
Pada analisis dengan axiomatic design, matriks desain yang diterima adalah yang memenuhi aksioma pertama (independence axiom) bahwa setiap fungsi mungkin dapat diselesaikan secara terpisah dari fungsi yang lain dengan parameter desain (DP) yang 
terpisah pula. Desain matriks yang diterima atau memenuhi aksioma pertama adalah uncoupled design dan decoupled design bila urutan desainnya tepat. Hubungan dibentuk mengikuti persamaan berikut:

$$
\{\mathrm{FR}\}=[\mathrm{A}]\{\mathrm{DP}\}
$$

dengan FR adalah functional requirement, A adalah matriks desain yang menjadi karakter dari desain, dan DP adalah parameter desain.

Pada industri kecil terdapat dua matriks desain yang tidak memenuhi aksioma pertama sehingga perlu didekomposisi lebih lanjut agar lebih mudah ditangani, yaitu domain penerapan teknologi produk dengan inovasi produk, dan domain place dengan tim marketing. Pada industri menengah terdapat satu matriks desain yang tidak memenuhi aksioma pertama yaitu domain place dan promotion dengan tim marketing.

Berdasarkan proses pembangunan kerangka kerja yang telah dilakukan pada dua kelompok IKM, dapat diketahui bahwa adaptasi metode dapat efektif dan memadai bagi proses perencanaan pengembangan produk baru IKM. Hal tersebut didasarkan pada penggunaan waktu analisis metode dan dekomposisi fungsional yang dapat dilaksanakan secara paralel, serta keterlibatan sumber daya manusia yang sedikit dalam analisis pada setiap pendekatan yang dilakukan.

\section{Evaluation}

Tahapan ini membahas tentang implementasi tiga metode dekomposisi fungsional pada industri kecil dan menengah. Pada penerapan pugh selection matrix, setiap konsep teknis diberikan bobot penilaian, sehingga dapat diketahui tingkat prioritas setiap konsep teknis. Berdasarkan evaluasi, pugh selection matrix ditemukan batasan, yaitu tidak dapat mendeskripsikan konsep teknis kedalam domain fungsi dan sarana yang lebih lengkap dan detail, sehingga diperlukan dukungan metode dekomposisi yang lain.

Metode Function means tree merupakan metode yang sederhana dalam membangkitkan domain fungsi dan sarananya hingga ke tingkatan khusus, tetapi tidak memberikan bobot prioritas dari konsep teknis.

Pada metode axiomatic design, setiap domain fungsi dan parameter desain harus memiliki hubungan yang independen, sehingga parameter desain tidak akan saling tumpang tindih dan mempengaruhi satu sama lain, yang berpengaruh pada proses desain yang lebih mudah ditangani. Setiap metode memiliki kelebihan dan kekurangan dalam penerapannya, seperti ditunjukkan dalam Tabel 3. berikut.

Tabel 3. Kelebihan dan Kekurangan Metode Dekomposisi

\begin{tabular}{|c|c|}
\hline Kelebihan & Kekurangan \\
\hline \multicolumn{2}{|c|}{ Function Means Tree } \\
\hline 1. Sederhana, cepat, dan SDM sedikit. & 1. Reliabilitas rendah. \\
\hline 2. Tidak membutuhkan metode matematik. & 2. Dibutuhkan expert judgement. \\
\hline 3. Hasil general dan penerapan fleksibel. & \multirow{2}{*}{$\begin{array}{l}\text { 3. Tumpang tindih penerapan konsep yang } \\
\text { berdampak pada investasi \& biaya. }\end{array}$} \\
\hline 4. Fungsi dan sarana hingga paling khusus. & \\
\hline \multicolumn{2}{|l|}{ Pugh Selection Matrix } \\
\hline $\begin{array}{l}\text { 1. Penyaringan \& penilaian menghasilkan } \\
\text { prioritas konsep. }\end{array}$ & $\begin{array}{l}\text { 1. Dibutuhkan expert judgement untuk } \\
\text { mendapatkan hasil yang akurat. }\end{array}$ \\
\hline 2. Hasil yang objektif dan akurat. & 2. Pelaksanaan kompleks. \\
\hline \multirow{3}{*}{$\begin{array}{l}\text { 3. Penolakan konsep lebih percaya diri pada } \\
\text { konsep dengan informasi yang lebih sedikit. }\end{array}$} & 3. Informasi harus lengkap setiap konsep. \\
\hline & $\begin{array}{l}\text { 4. Membutuhkan waktu untuk mencari fakta } \\
\text { dan informasi sebuah konsep. }\end{array}$ \\
\hline & 5. Kemungkinan tumpang tindih konsep. \\
\hline
\end{tabular}




\begin{tabular}{l|l}
\hline \multicolumn{1}{c|}{ Kelebihan } & \multicolumn{1}{c}{ Kekurangan } \\
\hline \multicolumn{2}{|c}{ Axiomatic Design } \\
\hline $\begin{array}{l}\text { 1. Hasil lebih detail pada setiap konsep. } \\
\begin{array}{l}\text { 2. Menyediakan informasi yang detail dan akurat } \\
\text { dari setiap sarana. }\end{array}\end{array}$ & $\begin{array}{l}\text { 1. Melibatkan setiap bagian perusahaan. } \\
\text { dalam menyusun matriks }\end{array}$ \\
\hline $\begin{array}{l}\text { 3. Tidak terjadi tumpang tindih dalam } \\
\text { pelaksanaan fungsi dan sarana. }\end{array}$ & $\begin{array}{l}\text { 3. Memerlukan keahlian tambahan dalam } \\
\text { mengolah matriks. }\end{array}$ \\
\hline $\begin{array}{l}\text { 4. Memungkinkan peneliti mengetahui } \\
\text { hubungan setiap fungsi \& sarananya. }\end{array}$ & 4. Waktu analisis yang lebih lama (time consume). \\
\hline
\end{tabular}

\section{Conclusion}

Tahapan ini memberikan informasi akhir terkait hasil evaluasi dari implementasi adaptasi metode MFD, yang terdiri dari penerapan house of quality, dan dekomposisi fungsional. Validitas pragmatis dilakukan dalam penerapan setiap metode dengan mempertimbangkan batasan dan kendala dari IKM, dan penerapan metode dekomposisi dari penelitian terdahulu.

Dapat diambil saran bahwa kerangka kerja perencanaan pengembangan produk baru yang efektif dan memuaskan untuk diterapkan pada IKM, yaitu terdiri dari dua tahapan. Tahapan pertama yaitu pembangunan house of quality (HoQ) yang mendeskripsikan keinginan konsumen ke dalam konsep teknis. Tahapan kedua yaitu dekomposisi fungsional dari konsep teknis dengan pugh selection matrix. Dilakukan penambahan dekomposisi fungsional lain untuk mendapatkan analisis yang efektif, dengan diterapkan secara paralel, yaitu dekomposisi konsep dengan metode function means tree, dan sintesa solusi teknis dengan metode axiomatic design yang memberikan informasi terkait posisi domain sarana teknis terhadap pemenuhan fungsi secara spesifik dan independen, sehingga proses desain lebih mudah ditangani.

\section{SIMPULAN}

Proses pembangunan kerangka kerja menghasilkan dua tahapan yang efektif diterapkan IKM. Tahapan pertama adalah deskripsi konsep teknis, yang mendeskripsikan kebutuhan konsumen menjadi karakteristik (konsep) teknis menggunakan house of quality. Tahapan kedua adalah dekomposisi fungsional dari konsep teknis, menggunakan pugh selection matrix, function means tree, dan axiomatic design, yang dilakukan secara paralel.

Saran untuk penelitian selanjutnya adalah proses pengumpulan data voice of customer dapat ditunjang dari data base customer relationship management. Proses pengumpulan data perlu peran aktif dan keterbukaan informasi dari setiap departemen yang ada di perusahaan agar data yang didapatkan lebih akurat dan objektif. Penerapan tahapan kedua kerangka kerja, yaitu pada dekomposisi fungsional, proses zigzagging dapat dieliminasi karena telah dilakukan pada function means tree. Langkah ini dapat menurunkan penggunaan waktu analisis.

\section{DAFTAR PUSTAKA}

A. Erlandsson, "Effective Product Planning - Product Planning in combination with modular product design enables a co-ordinated efficient development of products and manufacturing system in Swedish," Licentiate Thesis. The Royal Institute of Technology. Stockholm, 1993.

A. Griffin and J. R. Hauser, "The Voice of the Customer," Mark. Sci., 1993.

A. J. Robotham, "The use of function/ means trees for modelling technical, semantic and business functions," J. Eng. Des., vol. 13, no. 3, pp. 243-251, Sep. 2002.

A. Thakker, J. Jarvis, M. Buggy, and A. Sahed, "3DCAD conceptual design of the next-generation impulse turbine using the Pugh decision-matrix," 
Mater. Des., vol. 30, no. 7, pp. 2676$2684,2009$.

A. Uppalanchi, "Application of Quality Function Deployment in new product and service development Presented to the Faculty of the Graduate School of the In Partial Fulfillment of the Requirements for the Degree," 2010.

B. Cerit, G. Küçükyazıcı, and G. Kalem, "Quality Function Deployment and Its Application on a Smartphone Design," Balk. J. Electr. Comput. Eng., vol. 2, no. 2, pp. 86-91, 2014.

B. J. Hicks, S. J. Culley, R. D. Allen, and G. Mullineux, "A framework for the requirements of capturing, storing and reusing information and knowledge in engineering design," Int. J. Inf. Manage., vol. 22, no. 4, pp. 263-280, 2002.

Bisnis Indonesia, "DIY Perlu Kembangkan Industri Kreatif," 2018. [Online]. Available: http://semarang.bisnis. com/read/20180110/14/97279/ diy-perlu-kembangkan-industrikreatif. [diakses pada tanggal 17 Januari 2018].

D. H. Henard and D. M. Szymanski, "Why Some New Products Are More Successful Than Others," J. Mark. Res., vol. 38, no. 3, pp. 362-375, 2001.

D. Raudberget, "The Decision Process In Set-Based Concurrent EngineeringAn Industrial Case Study," Int. Des. Conf., pp. 937-946, 2010.

DetikFinance, "ini kendala yang dihadapi pelaku industri kreatif," 2016. [Online]. Available: https:// finance.detik.com/berita-ekonomibisnis/d- 3284282/ini-kendala-yangdihadapi-pelaku-industri-kreatif. [Accessed: 15-Jan-2018].

F. S. Borjesson, "Improved Output in Modular Function Deployment Using Heuristics," Proc. 17th Int. Conf.
Eng. Des., vol. 4 , no. 17 , pp. $24-27$, 2009.

G. Erixon, "Modular function deployment : a method for product modularisation," PhD. Thesis., KTH, Dept. of Manufacturing systems, 1998.

Hamdan, "Kebijakan Dan Strategi Pengembangan Ekonomi Kreatif," 2016.

J. D. Owens and J. Davies, "The Importance of a New Product Development (NPD) process: Getting Started.," 1st Eur. Conf. KM, no. 1995, pp. 1-12, 2000

J. D. Owens, "Why do some UK SMEs still find the implementation of a new product development process problematical?," Manag. Decis., vol. 45, no. 2, pp. 235-251, 2007.

J. F. Hair, W. C. Black, B. J. Babin, R. E. Anderson, and R. L. Tatham, "Multivariate Data Analysis," Prentice Hall. 2009.

J. Nicholas, A. Ledwith, and H. Perks, "New product development best practice in SME and large organisations: Theory vs practice," Eur. J. Innov. Manag., vol. 14, no. 2, pp. 227-251, 2011.

K. A. Fantazy and M. Salem, "The value of strategy and flexibility in new product development," J. Enterp. Inf. Manag., vol. 29, no. 4, pp. 525-548, 2016.

K. Osman, N. Bojčetić, and D. Marjanović, "Implementation of Modular Architecture of Cooling Generators," pp. 465-474, 2008.

K. Osman, N. Bojčetić, and D. Marjanović, "Multi Criteria Decision Making in Product Platform Development and Evaluation," Int. Des. Conf., pp. 1720, 2010.

K. P. Widagdo, "IKM di Indonesia: Permasalahan, dan Strategi Pengembangannya," 2014. [Online]. Available: http:// bdiyogyakarta. ke men perin.go.id / n ew s / post/2014/04/ 15/117/ikm-di- 
indonesia:-permasalahan-danstrategi-pengembangannya. [Accessed: 05-Nov-2017].

K. Perindustrian, "Inovasi Jadi Kunci Sukses IKM Berdaya Saing," 2016. [Online]. Available: http://www. kemenperin.go.id/artikel/16493/ Inovasi-Jadi-Kunci-Sukses-IKMBerdaya-Saing. [Accessed: 20-Mar2018].

M. A. Schilling, “Toward a general modular systems theory and its application to interfirm product modularity," Acad. Manag. Rev., vol. 25, no. 2, pp. 312-334, 2000.

M. Israr and A. Gangele, "A Quality function deployment methodology for product development," Int. J. Emerg. trends Eng. Res., vol. 2, no. June, pp. 52-63, 2014.

M. Onori, H. Alsterman, and J. Barata, "An architecture development approach for evolvable assembly systems," (ISATP 2005). 6th IEEE Int. Symp. Assem. Task Plan. From Nano to Macro Assem. Manuf. 2005., pp. 1924, 2005.

M. U. Anielozie and S. A. Mostafavi, "Incorporating Customer Needs into Products - A Case Study in an FMCG Company," Master's Thesis in Production Engineering and Management at Department of Production Engineering KTH Royal Institute of Technology, 2012.
P. Holzner, E. Rauch, P. R. Spena, and D. T. Matt, "Systematic Design of SME Manufacturing and Assembly Systems Based on Axiomatic Design," Procedia CIRP, vol. 34, pp. 81-86, 2015.

R. G. Cooper and E. J. Kleinschmidt, “2 New Product Performance: What Distinguishes the Star Products," Aust. J. Manag., vol. 25, no. 1, pp. 17-46, 2000.

R. G. Cooper, "The Dimensions of Industrial New Product Success and Failure," J. Mark., vol. 43, no. 3, p. 93, 1979.

S. Ahmedova, "Factors for Increasing the Competitiveness of Small and Medium- Sized Enterprises (SMEs) in Bulgaria," Procedia - Soc. Behav. Sci., vol. 195, pp. 1104-1112, 2015.

S. L. Chan and W. H. Ip, "A dynamic decision support system to predict the value of customer for new product development," Decis. Support Syst., vol. 52, no. 1, pp. 178-188, 2011.

T. Runhua, "The Conceptual Design of a Fast Clasping Mechanism Based on Function Means Tree and TRIZ," TRIZ J., 2000.

W. L. Kuechler and V. K. Vaishnavi, "A Framework for Theory Development in Design Science Research: Multiple Perspectives," J. Assoc. Inf. Syst., vol. 13, no. 6, pp. 395-423, 2012.

Z. Ayag, "An integrated approach to concept evaluation in a new product development," J Intell Manuf, 2014. 